\title{
Friedreich's Ataxia with Dysautonomia and Labile Hypertension
}

\author{
D. Margalith, H.G. Dunn, J.E. Carter and J.M. Wright
}

\begin{abstract}
SUMMARY: An Amerindian girl with Friedreich's ataxia presented at the age of 14 years with intermittent bifrontal headaches and abdominal aching, often associated with nausea and recurrent vomiting and an evanescent pink, blotchy rash on the upper trunk. In these attacks she also had hypertension up to $210 / 160 \mathrm{~mm} \mathrm{Hg}$. Renal function studies, including intravenous pyelogram and angiography, were normal. Plasma renin activity $(2.5 \mathrm{ng} / \mathrm{ml} / \mathrm{hr})$ was also normal. Total body CT scan was negative for phaeochromocytoma, and repeated estimations of 24-hour excretion of urinary VMA were normal or borderline high. Levels of total catecholamines in 24-hour urine were normal twice, but two random specimens during the paroxysmal episodes contained abnormally high levels of norepinephrine and dopamine. Plasma catecholamine concentrations were increased but not as high as with phaeochromocytoma. Blood pressure monitoring demonstrated marked fluctuations with position and temperature. A clonidine suppression test showed a substantial fall of plasma catecholamine levels, consistent with dysautonomia and not with phaeochromocytoma. It is concluded that the patient has dysautonomia of central origin, probably as a manifestation of Friedreich's ataxia. These findings are discussed in relation to the recent demonstration of increased levels of plasma catecholamines in that disease.
\end{abstract}

RÉSUMÉ: Nous présentons I'histoire d'une jeune Amérindienne souffrant d'ataxie de Friedreich qui, à lâge de 14 ans présenta des céphalées bifrontales intermittentes et des douleurs abdominales souvent associées à des nausées, des vomissements répétitifs et une éruption rosâtre, inconstante au tronc supérieur. Lors de ces attaques, une hypertension fut notée qui atteignait des niveaux de $210 / 160 \mathrm{~mm} \mathrm{Hg}$. Les études de la fonction rénale, y compris le pyélogramme intraveineux et l'angiographie furent normales, ainsi que l'activité de la rénine plasmatique $(2.5 \mathrm{ng} / \mathrm{ml} / \mathrm{h})$. Une tomodensitométrie corporelle totale s'avéra négative pour la présence d'un phéochromocytome et la détermination répétée de l'excrétion urinaire $(24 \mathrm{~h})$ de VMA fut normale ou à peine élevée. Les niveaux de catécholamines urinaires (collection de $24 \mathrm{~h}$ ) furent normaux à 2 reprises, mais deux échantillons pris au hasard d'épisodes paroxystiques révélèrent des taux élevés de norépinéphrine et de dopamine. Les catécholamines plasmatiques étaient élevées, mais moins que dans le phéochromocytome. La surveillance de la tension artérielle montra des fluctuations importantes avec la position et la température. Un test de suppression à la clonidine montra une diminution des taux de catécholamines plasmatiques, ce qui est compatible avec une dysautonomie plutôt qu'un phéochromocytome. Nous concluons que la patiente avait une dysautonomie d'origine centrale, probablement en relation avec sa maladie de Friedreich. Nous discutons ces résultats à la lumière de la démonstration récente de taux plasmatiques élevés de catécholamines dans cette maladie.

Can. J. Neurol. Sci. 1984; 11:73-77

Friedreich's ataxia is a heredo-degenerative disorder of the nervous system characterized by "dying back" of axons with eventual disintegration of nerve cells in several neuronal systems. These include large diameter myelinated sensory fibres derived from cells of the dorsal root ganglia, the posterior columns of spinal cord, spino-cerebellar tracts and cortico-spinal tracts. Various cranial nerves may also be involved. In addition to the neurological abnormalities patients can develop a hypertrophic cardiomyopathy, scoliosis, pes cavus and other skeletal deformities.

There is relatively little information in the literature with respect to involvement of the autonomic nervous system in this disease. Guillain and Mollaret (1932) postulated sympathetic overactivity as a cause for the cardiomyopathy and this is supported by the observations of impaired blood flow in the extremities, inappropriate sinus tachycardia with pronounced orthostatic pulse reaction, and increased heart rate response to stress in patients with Friedreich's ataxia (Thorén, 1964, Cote et al., 1976). However, the existence of increased sympathetic tone in Friedreich's ataxia has been questioned (Urich et al., 1957, Hewer, 1969), and to our knowledge hypertension has not been described in association with the cardiomyopathy (Greenfield, 1954, Thorén, 1964, Tyrer and Sutherland, 1969, Tyrer, 1975). Recently there has been renewed interest in the possibility of sympathetic overactivity in Friedreich's ataxia, especially since some workers (Stanton et al., 1969, Laks et al., 1973, Cohen, 1974, Karliner et al., 1981) have implicated catecholamines in the etiology of a cardiomyopathy in animals which is similar to that frequently seen in Friedreich's ataxia. Finally, concentrations of free plasma norepinephrine, epinephrine and dopamine have been found to be significantly higher in patients with Friedreich's ataxia than in controls (Pasternac et al., 1982, Merkel and Barbeau, 1982).

As further evidence for autonomic dysfunction in this disorder we report here the occurrence of dysautonomia and labile hypertension in a girl with Friedreich's ataxia.

\section{Case Report}

The patient, now aged 20 years, first developed neurological symptoms at 3 years. She was the sixth of seven children born to an Amerindian mother who had two offspring in her first and five in the second marital

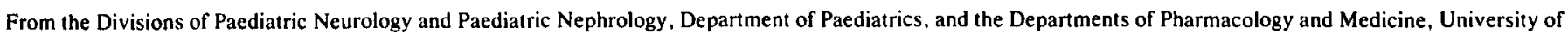
British Columbia, Vancouver. Canada

Received May 16. 1983. Accepted in revised form September 5, 1983

Reprint requests to: Dr. H.G. Dunn, Division of Neurology, Department of Paediatrics, Children's Hospital, 4480 Oak Street, Vancouver, B.C. V6H 3V4, Canada 
relationship. There was no known consanguinity between the parents The other children were all reported to be healthy, although the two older boys had had poliomyelitis in childhood and the oldest halfbrother had some seizures in infancy. The mother suffered from ulcerative colitis and at 30 years had a cerebral hemorrhage with left-sided hemiparesis which resolved almost completely. The mother's maternal uncle was an epileptic and mentally retarded; he died after a seizure. There was no family history of hypertension.

The child was born at term after a pregnancy complicated by frequent bleeding. Delivery was normal, birth weight $2790 \mathrm{gram}$. The neonatal course was unremarkable. According to the mother she passed her milestones of development slightly more slowly than her siblings, but she walked freely at 14 months. At 3 years she was noted to have a stumbling gait and to trip easily.

When she was first examined by one of us (H.G.D.) at 5 years 11 months, she had clumsy arm movements, gait ataxia and diminished vibration and touch sensation in the feet. The deep tendon reflexes were absent. At that time her spinal fluid showed only 2 white blood cells (WBC) $/ \mathrm{mm}^{3}$ and normal levels of protein and glucose. Electrodiagnostic studies demonstrated normal conduction velocity in the motor fibres of the right median, ulnar and peroneal nerves but impaired conduction in the sensory fibres (see patient G.S., Dunn 1973). Psychological assessments at various ages have indicated low-average intelligence (WISC Verbal I.Q. of 90, Performance I.Q. of 96 and Full-Scale I.Q. of 92) with no change over time up to the age of 20 years.

The disease progressed slowly, and at age 7 years she first had a positive Romberg sign and was developing a scoliosis. The diagnosis of Friedreich's ataxia was then made. At age 13 she was noted to have an S-shaped dorsilumbar scoliosis, slight wasting of the small muscles of the feet, a mild ataxic dysarthria (staccato speech) and a partial sensorineural hearing loss in the left ear. She was mildly hypotonic, and her limb ataxia had become more marked. Deep tendon reflexes remained absent, and the plantar and Chaddock responses were equivocal. Sensation to light touch and vibration was reduced in the fingertips and in both feet, with very little residual vibration sense below the knees. Her gait was broad-based and ataxic, and Romberg sign was positive.

Laboratory investigations up to this age had given normal results for the following: complete blood count, urinalysis, plasma lactate, amino acid levels and ammonia, liver enzymes, leucocyte lysosomal enzymes (arylsulfatase A, $\alpha$-galactosidase, $\alpha$-glucosidase, $\alpha$-mannosidase, $\beta$-galactosidase and $\beta$-glucosidase), serum hexosaminidase ( $A$ and $B$ ), metabolic screening of urine for reducing substances, abnormal amino acids and excessive keto acids or mucopolysaccharides, routine spinal fluid examination (including gamma globulin and amino acid levels), and assessment of pyruvate dehydrogenase and ketoglutarate dehydrogenase activity in fibroblast culture. Further electrodiagnostic studies had confirmed the impairment of conduction in sensory fibres of limb nerves, and electromyography had begun to show evidence of partial denervation in tibialis anterior and extensor digitorum brevis. An electroencephalogram at 6 years had been suggestive of diffuse disturbance in cerebral function at a subcortical level, and at 13 years indicated mild paroxysmal dysrhythmia involving deep midline structures. Electrocardiogram and echocardiogram were normal. X-ray examination of skull showed no abnormality, and $x$-ray of the left hand and wrist indicated normal bone age. Skin biopsy for light and electron microscopy proved normal, without evidence of lysosomal storage.

At 14 years the girl began to have intermittent episodes of malaise, epigastric or peri-umbilical aching, nausea usually leading on to recurrent vomiting, and bifrontal headaches. These episodes became progressively worse, lasting for several days at a time and resulting in marked weight loss. (Height and weight were both more than 2 S.D. below the mean for her age).

The pulse rate was 90 per minute, blood pressure (B.P.) 120/80 supine; a soft (grade 1) ejection systolic murmur was heard at the left sternal border. Neurological examination showed the previous abnormalities but also an intention tremor in both hands, worse on the left. She demonstrated emotional lability and had frequent spells of crying. Stressful emotional experiences seemed to trigger or aggravate at least some of the episodes of vomiting. These attacks were associated with increased sweating over the face, neck and chest and with an evanescent pink, blotchy rash over the neck and upper trunk, tachycardia up to a rate of 120-140 per minute, and hypertension occasionally rising as high as $210 / 160$.

Further investigations, especially those to exclude a phaeochromocytoma and other organic causes of intermittent hypertension, were then arranged. Erythrocyte sedimentation rate, serum complement $\mathrm{C}_{3}$ and $C_{4}$, serum $T_{3}$ and $T_{4}$ levels and plasma renin activity $(2.5 \mathrm{ng} / \mathrm{ml} / \mathrm{hr})$ were normal and the serum was negative for anti-nuclear factor. Abdominal $\mathrm{X}$-rays and ultrasonogram (including renal) and two upper gastrointestinal series with follow-through proved normal. A barium enema was also unremarkable and did not show any evidence of malrotation to explain the intermittent vomiting. Renal function studies, intravenous pyelogram and renogram with ${ }^{131} I$ Hippuran were also normal. Abdominal angiograms showed normal renal and other abdominal arteries. Computerized tomography scans of head, chest, abdomen and pelvis were negative for pheochromocytoma or other abnormalities. Urine tests for 5-hydroxy indole acetic acid and porphobilinogen as well as screening for heavy metals were negative, and 24-hour excretion of urinary lead was in the normal range. Repeated estimations of 24-hour excretion of urinary vanillyl mandelic acid (VMA) were normal to borderline high, ranging from 2 to $9.5 \mathrm{mg} / 24 \mathrm{hr}$, with a mean of $5.3 \mathrm{mg} / 24 \mathrm{hr}$. 24-hour urinary excretion of catecholamines was $29-55 \mu \mathrm{g} / 24 \mathrm{hr}$ and thus within the normal range of $0-100 \mu \mathrm{g} / 24 \mathrm{hr}$. However, estimation of urinary norepinephrine and dopamine by the fluorometric method of McGeer et al. (1963) in random specimens during attacks of hypertension showed increased levels, namely norepinephrine 180 and $204 \mathrm{ng} / \mathrm{mg}$ creatinine (normal 24-79) and dopamine $544 \mathrm{ng} / \mathrm{mg}$ creatinine (normal 153-415). Thus these investigations failed to confirm any evidence of pheochromocytoma; however, urinary excretion of norepinephrine and dopamine was high during episodes of hypertension. Plasma catecholamines were measured in two blood samples, one taken while the girl was normotensive and the other while she was hypertensive. The plasma norepinephrine and epinephrine levels were high on both occasions, though higher during hypertension (Fig. 1). Finally, the clonidine suppression test (Bravo et al. 1981) showed a substantial suppression of plasma catecholamines (Table 1).

Assessment of the autonomic nervous system. The patient had marked fluctuations in her blood pressure from minute to minute, as shown by continuous graphic recording for $11 / 4$ hours. The B.P. values ranged from $95 / 50$ to $137 / 80 \mathrm{~mm} \mathrm{Hg}$ in the supine and from $85 / 40$ to $110 / 80 \mathrm{~mm}$ $\mathrm{Hg}$ in the upright position. She occasionally had asymptomatic postural

CLINICAL RESEARCH HYPERTENSION LABORATORIES (Dopt. of Reseorch, Cleveland Clinic)

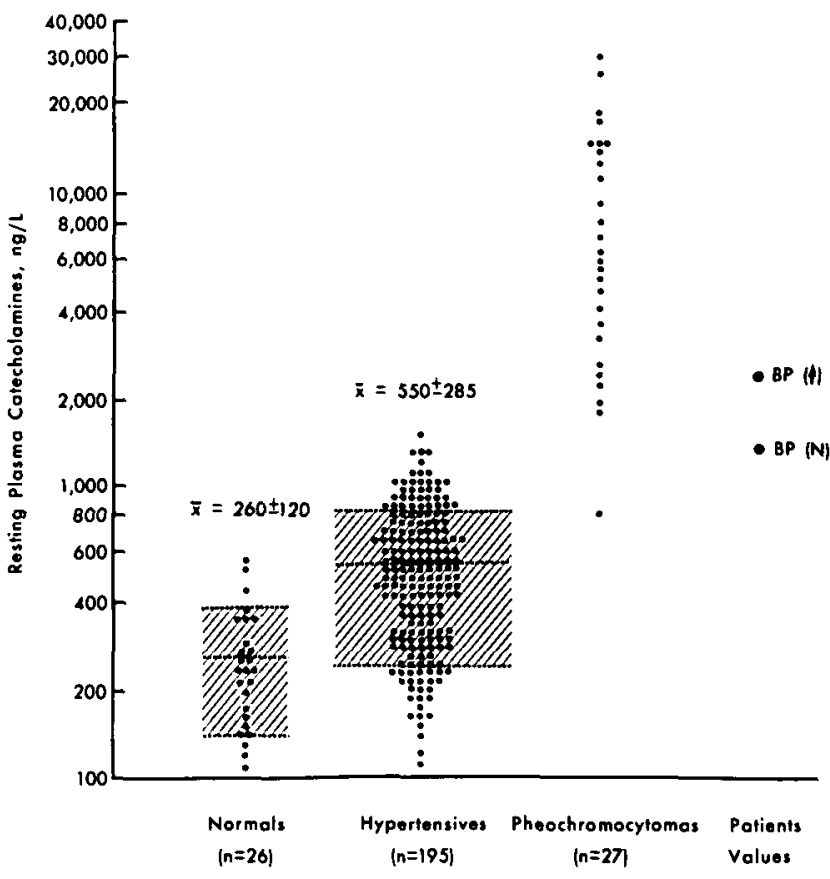

Figure I - Patient's resting plasma catecholamine levels with normal $(N)$ blood pressure (B.P.) and during an episode of hypertension ( 4 ) are shown on the right in comparison to range of values determined in normal persons, hypertensives and patients with phaeochromocytoma at the Clinical Research Laboratories of the Cleveland Clinic (Bravo et al. 1979). 


\section{COLD PRESSOR TEST}

\section{Hand In cold water}

Hand Out of cold water

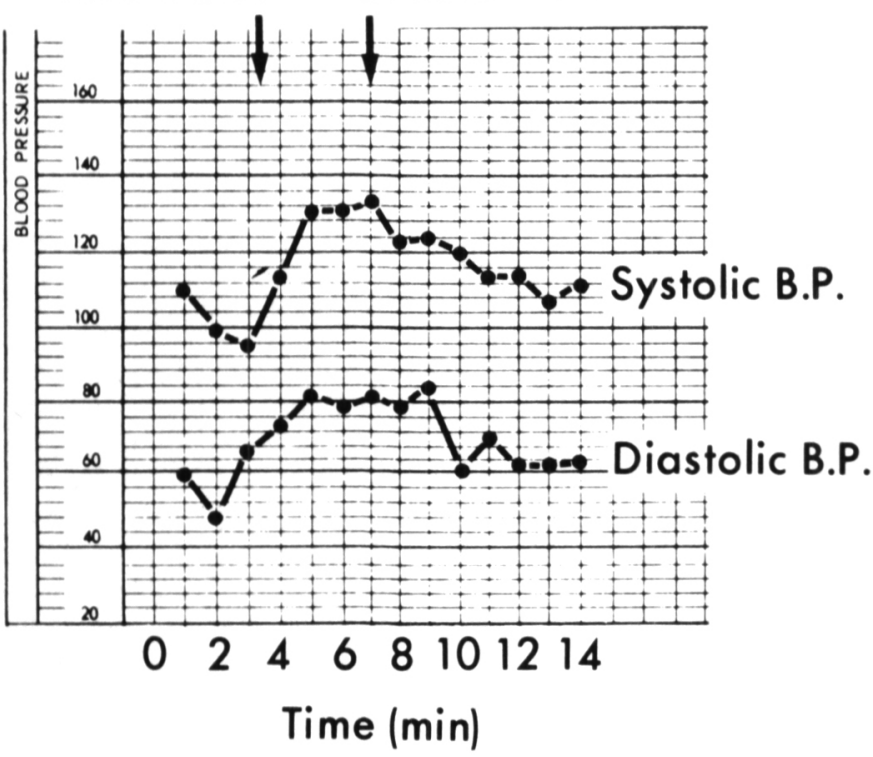

Figure 2 - Patient's cold pressor test.

hypotension with a fall of blood pressure from $120 / 80$ while supine to $80 / 50 \mathrm{~mm} \mathrm{Hg}$ upright. There was a normal rise of blood pressure on performing mental arithmetic (from $120 / 80$ to $130 / 90 \mathrm{~mm} \mathrm{Hg}$ ) and cooling of her hand (from $101 / 57$ to $126 / 80 \mathrm{~mm} \mathrm{Hg}$.) (Fig. 2). In one test of mental arithmetic the girl became very anxious and began to complain of malaise, nausea, epigastric pain and headache. Her face, neck and chest then became covered with a blotchy, pink rash (Fig. 3), the heart rate rose from 80 to 140 per minute and blood pressure from 120/80 to $200 / 140 \mathrm{~mm} \mathrm{Hg}$. There was no change in her alertness, and the paroxysmal features abated after a few hours of bed rest. Further assessment of the autonomic nervous system showed that she had a normal decrease of heart rate on ocular compression, a normal increase of sweating in response to rise of body temperature and a normal triple response to intradermal histamine injection. Digital pulse plethysmogram had a normal contour with a normal variation of fingertip volume with respiration and a normal decrease in fingertip volume on immersion of the contralateral hand in ice cold water.

Treatment. Various medications were tried. Intramuscular chlorpromazine ( 25 to $37.5 \mathrm{mg}$ ) or intramuscular reserpine $(3 \mathrm{mg}$ ) usually caused a resolution of the intermittent symptoms. Various combinations of chlorpromazine, propranolol, hydralazine, hydrochlorothiazide and reserpine orally were not effective in prevention. The use of labetalol, an $\alpha$ and $\beta$ blocker (Richards and Prichard, 1978) was transiently effective. On treatment with a combination of labetalol $400 \mathrm{mg} .3$ times daily, hydralazine $25 \mathrm{mg}$. 3 times daily and prazosin hydrochloride $5 \mathrm{mg}$. twice daily, her blood pressure was fairly well controlled, but she still had paroxysmal hypertension about once every 3 weeks. Clonidine $0.2 \mathrm{mg}$ twice daily proved more successful in preventing the paroxysmal hypertension and nausea. Attempts at modifying her surroundings and dealing with her anxieties had little success, particularly as she was increasingly incapacitated by her ataxia. Currently at 20 years, she is wheelchair-bound, but has no evidence of cardiomyopathy. A trial of lecithin in a dosage of up to $30 \mathrm{~g} /$ day for $2 \frac{1}{2}$ years did not seem to alter the course of Friedreich's ataxia. Her current antihypertensive medication is clonidine $0.2 \mathrm{mg}$. twice daily. During a recent episode of hypertension (B.P. 180/120) she was noted to have a 20 second episode when she was unresponsive and had minor head nodding, nausea and vomiting. She was amnesic for the episode later. An EEG during that period showed a normal alert background with an abrupt transient (1 minute) diffuse slowing without focal features following the above episode. It was concluded that this episode was probably secondary to the acute hypertension.
Table 1: Clonidine Suppression Test (0.3 mg. clonidine p.o.)

\begin{tabular}{cccc}
\hline \hline Time & B.P. & $\begin{array}{c}\text { Plasma } \\
\text { norepinephrine }\end{array}$ & $\begin{array}{c}\text { Plasma } \\
\text { epinephrine }\end{array}$ \\
\hline $0 \mathrm{~min}$. & $130 / 90$ & $278 \mathrm{ng} / \mathrm{L}$ & $33 \mathrm{ng} / \mathrm{L}$ \\
$30 \mathrm{~min}$. & $125 / 80$ & $229 \mathrm{ng} / \mathrm{L}$ & $36 \mathrm{ng} / \mathrm{L}$ \\
$70 \mathrm{~min}$. & $95 / 62$ & $59 \mathrm{ng} / \mathrm{L}$ & $<25 \mathrm{ng} / \mathrm{L}$ \\
$90 \mathrm{~min}$. & $95 / 57$ & $105 \mathrm{ng} / \mathrm{L}$ & $<25 \mathrm{ng} / \mathrm{L}$ \\
$120 \mathrm{~min}$. & $105 / 70$ & $173 \mathrm{ng} / \mathrm{L}$ & $27 \mathrm{ng} / \mathrm{L}$ \\
$180 \mathrm{~min}$. & $102 / 60$ & $144 \mathrm{ng} / \mathrm{L}$ & $<25 \mathrm{ng} / \mathrm{L}$ \\
\hline
\end{tabular}
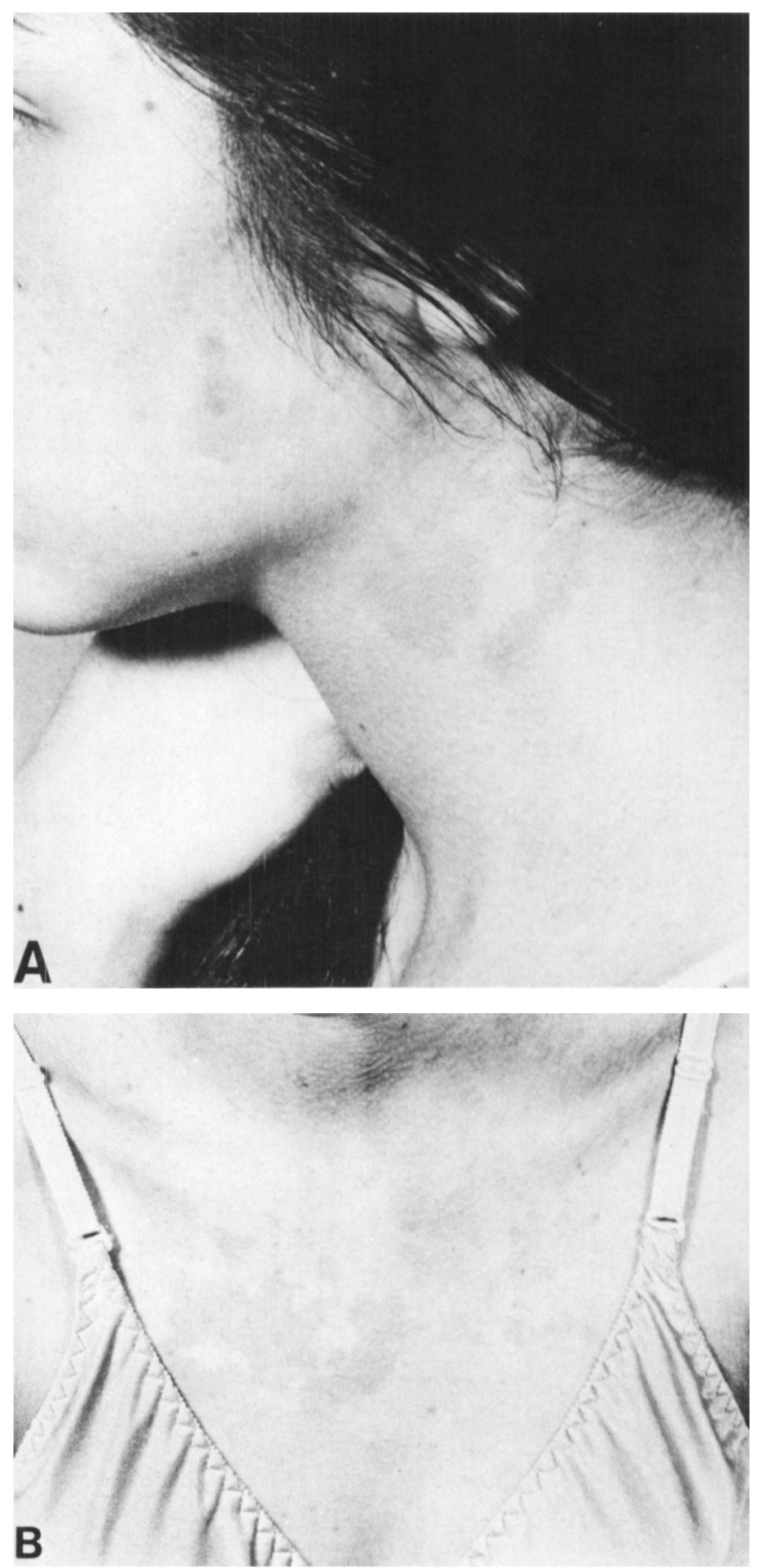

Figure 3 - Evanescent blotchy pink rash over the face and neck ( $A$ ) and upper chest $(B)$. 


\section{Discussion}

Our patient fulfills the obligatory criteria for the diagnosis of Friedreich's ataxia outlined by Geoffroy et al. (1976), i.e. onset before the end of puberty, progressive gait ataxia, dysarthria, loss of joint position or vibration sense, absent tendon reflexes in the legs, and muscle weakness. Of the secondary features, said to be present in more than $90 \%$ of cases, she lacks extensor plantar responses and evidence of cardiomyopathy but has pes cavus and scoliosis. The clinical course of the disorder has been quite characteristic apart from the superadded paroxysmal episodes of abdominal aching, nausea and vomiting, frontal headaches, blotchy rash of upper trunk and neck, and sweating accompanied by tachycardia and hypertension.

These episodes are best explained as manifestations of autonomic dysfunction. The repeatedly normal amount of urinary vanillylmandelic acid (VMA) and particularly the lowering of plasma catecholamine levels by clonidine exclude the possibility of pheochromocytoma (Bravo et al., 1981). Some of the paroxysmal features, particularly the skin rash and hypertension, may occur in faniilial dysautonomia (Riley, 1957), but the racial origin of the patient, the presence of tears and other clinical findings exclude that diagnosis. Extensive investigations ruled out other primary causes of hypertension, such as renal and renal vascular disease, collagen and adrenocortical disorders.

Is there any relationship between the paroxysmal dysautonomia and the Friedreich's ataxia in this patient? In the literature it is frequently stated that hypertension is not a feature of this disease even with cardiomyopathy (Heck, 1963; Thorén, 1969; Cote et al., 1976; Huxtable, 1978). Bell and Carmichael (1939) concluded that visceral disturbances, such as incontinence of urine or faeces, difficulties in micturition, and gastric pain or vomiting were reported so rarely in Friedreich's ataxia that their occasional association with the disease seemed of little significance. Heck (1964) considers that autonomic dysfunction is rare but may appear in advanced stages of the disease. On the other hand, it is known that patients with Friedreich's ataxia have impaired blood flow in the extremities (Heck, 1963; Thorén, 1969) and relatively low skin temperature in the legs (Dunn, 1973). As mentioned previously, it has been postulated that increased sympathetic activity may be a cause of the cardiomyopathy.

It has been reported that the heart rate in Friedreich's ataxia tends to increase excessively with light stress (Thorén, 1964; Cote et al., 1976). Increased sensitivity of the cardiac beta receptors to catecholamines has been suggested as an explanation for this phenomenon (Huxtable, 1978). Despite the clinical suggestions of increased sympathetic activity, urinary excretion of catecholamines has not been found to be increased in this disease (Thorén, 1964; Campanella et al., 1980), but the recent finding of a significant elevation in the mean level of free plasma catecholamines (Pasternac et al., 1982; Merkel and Barbeau, 1982) does raise the possibility that patients with Friedreich's ataxia may have a central autonomic nervous system dysfunction with increased sympathetic tone. In our patient the fact that clonidine, which acts on the central nervous system, was effective in lowering the blood pressure and the level of plasma catecholamines and in preventing paroxysmal episodes is in favour of a central cause for the disorder. In addition, it appeared that even emotional stress, like mental arithmetic, aggravated and occasionally triggered her paroxysmal hypertension and the associated symptoms. It is known that mental arithmetic (Brod et al., 1949), psychological stress (Herrmann et al., 1976), and suppressed anger (Harburg et al., 1973) may raise blood pressure, but not to the extent as in this patient nor with the same associated symptoms. Thus we may conclude that our patient's paroxysmal attacks are best explained by dysautonomia of central origin, aggravated and occasionally triggered by emotional stress.

\section{ADDENDUM}

After this paper had been submitted for publication, the patient, now aged 21 years, was readmitted in another episode of dysautonomia. On this occasion cardiovascular examination revealed normal pulses but a tachycardia of 160 per minute and a blood pressure of $150 / 90 \mathrm{~mm} \mathrm{Hg}$. The precordium was hyperactive with palpable heart sounds and a systolic thrill. On auscultation both heart sounds were loud and there was a Grade IV/VI ejection systolic murmur at the left sternal border radiating to both bases. The echocardiogram showed tachycardia and suggested anterior motion of the mitral valve in systole. There was aortic valve flutter and partial early closure.

The following morning the patient's symptoms had subsided and her heart rate was 90 per minute. The precordium was now normal on palpation. The heart sounds were both normal and there was only a Grade I/VI systolic murmur. The m-mode echocardiogram showed no evidence of systolic anterior motion of the mitral valve and no aortic valve flutter. The septal wall thickness was $1.3 \mathrm{~cm}$ and the left ventricular posterior wall thickness was $1.0 \mathrm{~cm}$. Two-dimensional echocardiography showed some thickening at the anterolateral part of the septum near the left ventricular outflow tract on the short axis view, and the septum appeared to be bulging in the subaortic region on the long axis view. These findings suggest that she has some features of hypertrophic cardiomyopathy and that she has a labile gradient which may be unmasked by increased sympathetic activity.

(The authors are indebted to Dr. G.G.S. Sandor for these observations.)

\section{ACKNOWLEDGEMENTS}

The authors wish to thank Dr. E.L. Bravo. Research Division, Cleveland Clinic, for performing the estimations of plasma catecholamines and for permission to use his data, and Dr. E.G. McGeer, Kinsmen Laboratory of Neurological Research, Faculty of Medicine. University of British Columbia, for performing the estimations of urinary catecholamines.

\section{REFERENCES}

Bell, J. and Carmichael, E.A. (1939). On hereditary ataxia and spastic paraplegia. In: Treasury of Human Inheritance, Cambridge University Press, vol. IV, part III, pp. 141-281.

Bravo, E.L., Tarazi, R.C., Gifford, R.W. and Stewart, B.H. (1979). Circulating and urinary catecholamines in pheochromocytoma. Diagnostic and pathophysiological implications. N. Eng. J. Med. 301:682-686.

Bravo, E.L., Tarazi, R.C., Fouad, F.M., Vidt, D.G. and Gifford, R.W., Jr. (1981). Clonidine suppression test - a useful aid in the diagnosis of pheochromocytoma. N. Eng. J. Med. 305:623-626.

Brod, J., Fencl, V., Hejl, Z. and Jirka, J. (1959). Circulatory changes underlying blood pressure elevation during acute emotional stress (mental arithmetic) in normotensive and hypertensive subjects. Clin. Sci. 18:269-279.

Campanella, G., Filla, A., DeFalco, F., Mansi, D., Durivage, A. and Barbeau, A. (1980). Friedreich's ataxia in South Italy: A clinical and biochemical survey of 23 patients. Can. J. Neurol. Sci. 7:351-357.

Cohen, J. (1974) Role of endocrine factors in the pathogenesis of cardiac hypertrophy. Circ. Res. 35 (Suppl. II): 49-57.

Cote, M., Davignon, A., Peckodrouin, K., Solignac, A., Geoffroy, G., Lemieux, B. and Barbeau, A. (1976). Cardiological signs and symptoms in Friedreich's ataxia. Can. J. Neurol. Sci. 3:319-322.

Dunn, H.G. (1973) Nerve conduction studies in children with Friedreich's ataxia and ataxia-telangiectasia. Dev. Med. Child Neurol. 15:324-337. 
Geoffroy, G., Barbeau, A., Breton, G., Lemieux, B., Aube, M., Leger, C. and Bouchard, J.P. (1976). Clinical description and roentgenologic evaluation of patients with Friedreich's ataxia. Can. J. Neurol. Sci. 3:279-286.

Greenfield, J.G. (1954). The Spino-Cerebellar Degenerations. Blackwell Scient. Publ., Oxford.

Guillain, G. and Mollaret, P. (1932). Le syndrome cardio-bulbaire de la maladie de Friedreich. Une des causes fréquentes de la mort dans cette affection. Presse Méd. 40 (ii): 1621-1624.

Harburg, E., Erfurt, J.C., Hanenstein, L.S., Chape, C., Schull, W.J. and Scherk, M.A. (1973). Socioecological stress, suppressed hostility, skin colour and black-white male blood pressure: Detroit. Psychosom. Med. 35:276-296.

Heck, A.F. (1963). Heart disease in Friedreich's ataxia. Part 1. Clinical studies and review of the literature. Neurology (Minneapolis), 13:587-595. Part II. Investigation of cardiac disease in a large family with Friedreich's ataxia. Neurology (Minneapolis), 13:596-600.

Heck, A.F. (1964). A study of neural and extraneural findings in a large family with Friedreich's ataxia. J. Neurol. Sci. 1:226-255.

Herrmann, H.J.M., Rassek, M., Schäfer, N., Schmidt, T. and Von Uexküll, T. (1976). Essential hypertension: problems, concepts and an attempted synthesis. In: Modern Trends in Psychosomatic Medicine, 3rd ed., O.W. Hill, editor, Butterworth, London.

Hewer, P.L. (1969). The heart in Friedreich's ataxia. Brit. Heart J., 31:5-14.

Huxtable, R.J. (1978), Cardiac pharmacology and cardiomyopathy in Friedreich's ataxia. Can. J. Neurol. Sci. 5:83-91.

Karliner, J.S., Alabaster, C., Stephens, H., Barnes, P. and Dollery, C (1981). Enhanced noradrenaline response in cardiomyopathic hamsters: possible relation to changes in adrenoceptors studied by radioligand binding. Cardiovasc. Res. 15:296-304.
Laks, M.M., Morady, F. and Swan. H.J. (1973). Myocardial hypertrophy produced by chronic infusion of sub-hypertensive doses of norepinephrine in the dog. Chest, 64:75-78.

McGeer, P.L., McGeer, E.G. and Wada, J.A. (1963). Central aromatic amine levels and behaviour. Arch. Neurol. 9:81-89.

Merkel, A.D. and Barbeau, A. (1982). Plasma catecholamines in Friedreich's ataxia assayed using high-performance liquid chromatography with electrochemical detection. Can. J. Neurol. Sci. 9:205-208.

Pasternac, A., Wagniart, P., Olivenstein, R., Petitclerc, R., Krol, R.. Andermann, E., Melancon, S.. Geoffroy, G.. deChamplain, J. and Barbeau, A. (1982). Increased plasma catecholamines in patients with Friedreich's ataxia. Can. J. Neurol. Sci. 9:195-203.

Richards, D.A. and Prichard. B.N.C. (1978). Concurrent antagonism of isoproterenol and norepinephrine after labelatol. Clin. Pharmacol. Ther. 23:253-258.

Riley, C.M. (1957). Familial dysautonomia. Adv. Pediatr. 9: 157-190.

Stanton, H.C., Brenner, G. and Mayfield. E.D. Jr. (1969). Studies on isoproterenol-induced cardiomegaly in rats. Amer. Heart J. 77:72-80.

Thorén, C. (1964). Cardiomyopathy in Friedreich's ataxia, with studies of cardiovascular and respiratory function. Acta Paediat. (Uppsala). 53 (Supp. 153):1-136.

Tyrer, J.H. and Sutherland, J.M. (1961). The primary spino-cerebellar atrophies and their associated defects, with a study of the foot deformity. Brain, 84:289-300.

Tyrer, J.H. (1975). Friedreich's ataxia. In: Handbook of Clinical Neurology, vol. 21:319-364. P.J. Vinken and G.W. Bruyn, editors. North Holland Publishing Co., Amsterdam.

Urich, H., Norman, R.M. and Lloyd, O.C. (1957). Suprasegmental lesions in Friedreich's ataxia. Confin. Neurol. (Basel) 17:360-371. 